\title{
Associations between postpartum fertility phenotypes and genetic traits in seasonal-calving, pasture-based lactating dairy cows
}

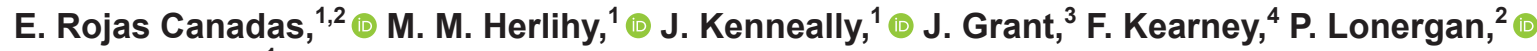 \\ and S. T. Butler ${ }^{1 *}$ (I) \\ ${ }^{1}$ Animal and Grassland Research and Innovation Centre, Teagasc, Moorepark, Fermoy, Co. Cork, Ireland, P61 C996 \\ ${ }^{2}$ School of Agriculture and Food Science, University College Dublin, Belfield, Dublin, Ireland, D04 N2E \\ ${ }^{3}$ Research Operations Group, Teagasc, Ashtown, Dublin 15, Ireland, D15 DY05 \\ ${ }^{4}$ Irish Cattle Breeding Association, Highfield House, Shinagh, Bandon, Co. Cork, Ireland, P72 X050
}

\section{ABSTRACT}

The objective of this study was to evaluate the associations between corpus luteum (CL) status, uterine health, body condition score (BCS), metabolic status, and parity at wk 3 and 7 postpartum in seasonal-calving, pasture-based, lactating dairy cows. The associations between those phenotypes and individual genetic traits were also evaluated. First- and second-parity spring-calving lactating dairy cows $(\mathrm{n}=2,600)$ from 35 dairy farms in Ireland were enrolled. Farms were visited every 2 weeks; cows that were at wk 3 (range 14 to 27 DIM) and wk 7 (range 42 to 55 DIM) postpartum were examined. Body condition score was measured using a scale of 1 to 5 with 0.25 increments. Transrectal ultrasound examination was performed at wk 3 and 7 postpartum to determine presence or absence of CL and ultrasound reproductive tract score. Blood samples were collected at each visit and the concentrations of glucose, $\beta$-hydroxybutyrate (BHB), and fatty acids (FA) were analyzed by using enzymatic colorimetry. Cows were grouped into 3 BCS categories [low $(\leq 2.5)$, target $(\geq 2.75$ and $\leq 3.25)$, and high $(\geq 3.5)] ; 2$ CL status categories: (present or absent); 2 uterine health status (UHS) categories (normal and abnormal); and 3 metabolic status categories [good (high glucose, low fatty acids and BHB), poor (low glucose, high fatty acids and BHB), and moderate (all other combinations)]. Fisher's exact test was used to test associations between variables and was supplemented by logistic regression. We found associations between UHS (wk 3 and 7), BCS (wk 3 and 7), parity (wk 3 and 7) metabolic status (wk 3), and predicted transmitting ability for calving interval (PTA for CIV; wk 3) and CL status. Cows that had abnormal UHS, low BCS, primiparity, and poor metabolic

Received November 15, 2018.

Accepted May 27, 2019.

*Corresponding author: stephen.butler@teagasc.ie status, and were in the quartile with the greatest PTA for CIV were less likely to have had CL present at wk 3 and 7 postpartum. We also found associations between CL status (wk 3 and 7), BCS (wk 3 and 7), parity (wk 3 and 7), and PTA for CIV (wk 3) and UHS. Cows that did not have a CL present had low BCS, primiparity, and that were in the quartile with greatest PTA for CIV, had a greater risk of abnormal UHS at wk 3 and 7 postpartum. We observed strong associations between CL status, UHS, BCS, metabolic status, parity, and individual genetic traits at wk 3 and 7 postpartum in seasonal-calving, pasture-based lactating dairy cows. Achieving target BCS and good metabolic status, and selecting cows based on PTA for CIV, are all expected to increase the likelihood of hastening the resumption of estrous cyclicity and enhancing uterine health during the postpartum period.

Key words: uterine infection, anestrus, phenotypic associations, genetic merit for fertility traits

\section{INTRODUCTION}

Pasture-based systems of milk production are based on maximizing the efficiency with which low-cost grazed grass is converted into milk (Hanrahan et al., 2018). These systems rely on a compact calving period in late winter and early spring to synchronize herd feed demand and seasonal changes in pasture growth rate. After parturition, the increase in milk energy output is faster than the increase in dietary energy intake, leading to a variable period of negative energy balance, which may extend for 8 to 12 wk until the beginning of the usual breeding period (Butler, 2003). During the postpartum period, cows must resume ovulatory ovarian activity, exhibit behavioral estrus, and become pregnant. In seasonal-calving dairy herds, cows that are not detected in estrus at the start of the breeding period are defined as anestrus (Rhodes et al., 2003). These cows may have had delayed ovulation (Andersen et al., 2004), ovulated without being detected in estrus, 
or calved late and not had sufficient time to resume estrous cycles before the seasonal breeding period. Successful ovulation of a dominant follicle during early lactation depends on pulsatile LH secretion to stimulate preovulatory follicular growth and estradiol secretion (Canfield and Butler, 1990), which eventually triggers an LH surge, behavioral estrus, and ovulation.

Uterine contamination during the periparturient period is unavoidable: 80 to $100 \%$ of cows have been reported to have bacteria in the uterine lumen during the first 2 wk postpartum (Sheldon et al., 2006). The development of uterine disease depends on the immune response of the cow, and on the species and number of bacteria involved (Sheldon et al., 2014). In addition, ovarian activity and luteal progesterone secretion modulate many of the processes that make a cow resistant or susceptible to uterine infection (Gilbert, 2011).

Subjective visual and tactile measurement of BCS and its temporal changes can be used to monitor nutritional status in cattle during the gestation-lactation cycle (Buckley et al., 2003. Body condition score at calving, nadir BCS, and the magnitude of BCS loss during the postpartum period are associated with milk production and reproduction in dairy cattle (Roche et al., 2009), but the influence of BCS on animal health remains poorly understood (Roche et al., 2013). Elevated concentrations of plasma fatty acids and BHB have been associated with impaired cow health (Ospina et al., 2010a), impaired liver function (Drackley et al., 2001), and reduced lymphocyte function (Lacetera et al., 2005). Postpartum examination of dairy cows is often undertaken around 15 to $30 \mathrm{~d}$ postpartum in confinement systems (LeBlanc et al., 2006) and before mating start date in pasture-based systems (Mee et al., 2009) to facilitate early clinical assessment and implement corrective measures if necessary.

In the 1980s, the rate of genetic improvement for milk production in Ireland was approximately $1.3 \%$ per year because of the introgression of North American Holstein Friesian genetics (Coffey, 1992). This resulted in a deterioration of genetic merit for fertility traits and suboptimal reproductive performance. To counteract this, a multi-trait selection index (economic breeding index) with a strong emphasis on fertility traits was developed and implemented in 2001 (Veerkamp et al., 2002).

In the present study, we recorded fertility phenotypes during the early postpartum period in lactating dairy cows. The objective was to evaluate the associations between ovarian corpus luteum (CL) status, uterine health, BCS, metabolic status, parity, and individual genetic traits at wk 3 and 7 postpartum in seasonalcalving, pasture-based lactating dairy cows.

\section{MATERIALS AND METHODS}

All experimental procedures involving cows were approved by the Teagasc Animal Ethics Committee and authorized by the Health Products Regulatory Authority, which is the competent authority in Ireland responsible for the implementation of European Union legislation (Directive 2010/63/EU) for the protection of animals used for scientific purposes.

\section{Herds and Experimental Design}

We conducted a prospective, observational crosssectional study on 35 pasture-based seasonal-calving dairy herds in the province of Munster, Ireland. In each herd, the study population included first-parity ( $\mathrm{n}=1,637)$ and second-parity $(\mathrm{n}=1,074)$ lactating dairy cows. All enrolled cows calved during the spring (February to April) in 2015 ( $\mathrm{n}=24$ herds) or 2016 ( $\mathrm{n}=11$ herds). Only cows that had calved at least $30 \mathrm{~d}$ before the planned farm mating start date were enrolled. Cows were withdrawn from the study if they had clinical signs of disease.

To collect data at the desired time points, researchers visited all enrolled herds every 2 wk during the postpartum period. The first exam was performed at wk 3 (14 to $27 \mathrm{DIM}$ ) and the second exam at wk 7 postpartum (42 to 55 DIM). At the wk 3 and 7 visits, postpartum ovarian structures and uterine health were evaluated by transrectal ultrasound (Ibex Pro 8.5-MHz transrectal transducer; EI Medical Imaging, Loveland, $\mathrm{CO})$. A single observer evaluated BCS using a scale of 1 to 5 ( $1=$ emaciated; $5=$ obese $)$ with 0.25 increments (Edmonson et al., 1989) and classified cows as low $(\mathrm{BCS} \leq 2.5)$, target $(2.75 \leq \mathrm{BCS} \leq 3.25)$ or high (BCS $\geq 3.5)$.

\section{Ultrasound Evaluation of Ovarian Status}

The presence or absence of a CL was recorded during the ultrasound evaluation. The group of cows identified as CL absent were further subdivided into anestrus [no $\mathrm{CL}$, and at least 1 large follicle $(>10 \mathrm{~mm})$ observed] or deep anestrus (no CL or large follicle observed). Cows with either a follicular cyst $(\geq 25 \mathrm{~mm}$ and no CL) or a luteal cyst $(\geq 25 \mathrm{~mm})$ were noted but removed from the analysis.

\section{Ultrasound Evaluation of Uterine Health}

We evaluated uterine health using an ultrasound reproductive tract score (URTS), classified as previously described by Mee et al. (2009): G1, a typical 
spoke-wheel-shaped lumen; G2, a spoke-wheel-shaped lumen with an enlarged center filled with a small volume (>2 mm, $\leq 5 \mathrm{~mm}$ diameter) of fluid of mixed echogenicity; G3, a stellate-shaped lumen filled with a moderate volume ( $>5 \mathrm{~mm}, \leq 10 \mathrm{~mm}$ diameter) of fluid of mixed echogenicity; G4, a circular lumen filled with a large volume ( $>10 \mathrm{~mm}$ diameter) of fluid of mixed echogenicity.

\section{Blood Sampling and Metabolic Status Assays}

Blood samples were collected at wk 3 and 7 postpartum from the coccygeal blood vessels into evacuated lithium heparin tubes (Vacutainer; Becton Dickinson, Wokingham, UK) and stored in a cooler during transportation. Plasma was separated following centrifugation $(1,500 \times g)$ and stored at $-20^{\circ} \mathrm{C}$. Plasma concentrations of glucose, BHB, and fatty acids were analyzed by enzymatic colorimetry (ABX Mira, Montpellier, France). Glucose kits were supplied by Horiba ABX (Montpellier, France); BHB kits were supplied by Randox Laboratories Ltd. (Crumlin, UK); fatty acid kits were supplied by Wako Chemicals GmBH (Neuss, Germany). Lactating dairy cows were categorized as having low glucose, high fatty acids, and high BHB when plasma concentrations of glucose were $<60.0$ $\mathrm{mg} / \mathrm{dL}$, fatty acids were $>0.60 \mathrm{mEq} / \mathrm{L}$, and $\mathrm{BHB}$ were $>0.76 \mathrm{mmol} / \mathrm{L}$, respectively, as reported by Garverick et al. (2013) and Ospina et al. (2010b).

\section{Data Handling and Statistical Analysis}

To evaluate the marginal associations between CL status, anestrous status, URTS, BCS, BCS change between wk 3 and 7 , metabolic status, parity, and genetic traits, we used Fisher's exact test. We used multiple logistic regression using the LOGISTIC procedure of SAS (version 9.3; SAS Institute Inc., Cary, NC) to test and correct for structure in the data (year, herd, and parity), and to calculate odds ratios (OR) and predicted probabilities. For each variable, a cohort of cows was designated as the reference group for determination of OR $(\mathrm{OR}=1)$. An OR of $>1$ implied increased likelihood and $\mathrm{OR}<1$ implied decreased likelihood of a particular outcome relative to the reference group. In addition, a binary uterine health status (UHS) variable was created to overcome problems with small numbers of cows with URTS of G1 $(\mathrm{n}=54)$ and G4 $(\mathrm{n}=22)$ at wk 3 and 7, respectively. At wk 3, G1 and G2 were classified as normal UHS, and G3 and G4 were classified as abnormal UHS. At wk 7, G1 was classified as normal, and all other URTS were classified as abnormal.

Multinomial and binary variables included depth of anestrus, UHS, BCS, BCS change, CL status change,
DIM at wk 3 exam, metabolic status, and genetic traits. The BCS change between wk 3 and 7 was assigned to 1 of 4 categories: lost $\geq 0.5$, lost $=0.25$, constant, or gained $\geq 0.25$. Corpus luteum status change was assigned 1 of 4 possible categories: CL-absent3_7 (CL not present at wk 3 or 7), CL-present3_7 (CL present at wk 3 and 7), CL-present7 (CL present at wk 7 only), and CL-present3 (CL present at wk 3 only).

We examined the effect of DIM at wk 3 to determine if DIM at the first visit influenced the results obtained. We assigned DIM at the wk 3 visit to 1 of 3 categories: early (14-18 DIM), mid (19-23 DIM), and late (24-28 DIM). We assigned blood indicators of metabolic status to 1 of 3 categories: good (high glucose, low fatty acids, and low BHB), poor (low glucose, high fatty acids, and high BHB), and moderate (all other possible combinations), respectively. At wk 7, because of the small number of cows in the poor category $(\mathrm{n}=66)$, we included only 2 groups in the metabolic status analysis: good and moderate plus poor combined.

The economic breeding index is divided into 7 subindexes: production, fertility, calving, beef, maintenance, management, and health (ICBF, 2018; https:/ /www.icbf.com/wp/). Each sub-index is composed of different individual traits. For this study, we selected the fertility sub-index and PTA values for the individual traits of calving interval (CIV; number of days between successive calving events), survival (longevity in the herd), milk kilograms and percentage protein in milk for inclusion in the analysis. Initially, separate logistic regression models were developed for the fertility sub-index and each individual genetic trait as continuous variables. Then, each genetic trait and the fertility sub-index were subsequently stratified into quartiles, and logistic regression models were used to calculate OR and predicted probabilities, including herd, year, and parity as fixed effects.

\section{RESULTS}

Herd and year were associated (both $P<0.001$ ) with each phenotype recorded, highlighting the importance of the herd differences and year-to-year environmental variation effects on the postpartum fertility phenotypes in pasture-based dairy systems.

\section{Number of Records}

Initially, 3,027 cows were enrolled in the study, but data for 427 and 582 cows were subsequently removed from wk 3 and 7 , respectively, because they were not fully compliant with the predesigned DIM for each exam (14 to 27 DIM at wk 3; and 42 to 55 DIM at wk 7 ) or they presented with a clinical disease. 


\section{Main Results for Each Phenotype}

Overall, a greater proportion $(P=0.001)$ of cows had CL present at wk $7(76.9 \%, 1,879 / 2,445)$ compared with wk $3(45.5 \%, 1,185 / 2,600)$. The incidences of cows with luteal and follicular cysts during the study period were $0.22 \%(6 / 2,711)$ and $3.8 \%(105 / 2,711)$, respectively. For variable CL status change, the percentage of cows with at least 1 CL at both wk 3 and wk 7 was $38.3 \%$ $(988 / 2,578)$ and the percentage of cows that did not have a CL at both wk 3 and 7 was $16.3 \%(422 / 2,578)$. The percentage of cows with at least 1 CL at wk 3 only was $7.7 \%(200 / 2,578)$, and the percentage of cows with at least 1 CL at wk 7 only was $37.4 \%(966 / 2,578)$.

The proportions of cows with URTS of G1, G2, G3, and G4 are summarized in Table 1 . At wk 3 and 7 postpartum, 27.3\% (712/2,600; G1 and G2) and 27.5\% (669/2,445; G1 only) of cows were classified as having normal UHS, respectively.

Most cows maintained BCS at the target score during the study period, with $89.5 \%(2,328 / 2,600)$ and $84.4 \%(2,066 / 2,445)$ of cows achieving target BCS at wh 3 and 7 , respectively. Of the remaining cows, $8 \%$ $(226 / 2,600)$ and $1.7 \%(46 / 2,600)$ at wk 3 and $14.5 \%$ $(355 / 2,445)$ and $0.9 \%(24 / 2,445)$ at wk 7 , had low and high BCS, respectively. Between wk 3 and 7 , the proportions of cows that had lost $\geq 0.5$, lost 0.25 , stayed constant or gained $\geq 0.25$ on BCS were $3.0 \%(87 / 2,192)$, $32.2 \%(706 / 2,192), 51.5 \%(1,131 / 2,192)$, and $12.2 \%$ $(268 / 2,192)$, respectively.

The proportions of cows with good, moderate, and poor metabolic status, respectively, were $35.6 \%$ $(818 / 2,294), 59.9 \%(1,376 / 2,294)$, and $4.3 \%(100 / 2,294)$ at wk 3 , and $53.5 \%(1,243 / 2,323), 46.0 \%(1,070 / 2,323)$, and $0.4 \%(10 / 2,323)$ at wk 7 . Overall, a greater proportion of cows had good metabolic status at wh 7
Table 1. Prevalence of ultrasound reproductive tract scores at wk 3 and 7 postpartum $^{1}$

Severity

of uterine

infection

Wk $3, \%$ (no.)

Wk $7, \%$ (no.)

\begin{tabular}{lll}
\hline G1 & $2.2(59 / 2,600)$ & $27.3(669 / 2,445)$ \\
G2 & $25.1(653 / 2,600)$ & $48.3(1,182 / 2,445)$ \\
G3 & $60.5(1,574 / 2,600)$ & $23.3(572 / 2,445)$ \\
G4 & $12.0(314 / 2,600)$ & $0.8(22 / 2,445)$ \\
\hline
\end{tabular}

${ }^{1} \mathrm{G} 1$ = spoke-wheel-shaped lumen; G2 = spoke-wheel-shaped lumen with an enlarged center filled with a small volume $(>2 \mathrm{~mm}, \leq 5 \mathrm{~mm}$ diameter) of fluid of mixed echogenicity; G3 = stellate-shaped lumen filled with a moderate volume $(>5 \mathrm{~mm}, \leq 10 \mathrm{~mm}$ diameter) of fluid of mixed echogenicity; G4 = circular lumen filled with a large volume (>10 mm diameter) of fluid of mixed echogenicity; wk $3=14$ to 27 DIM; wk $7=42$ to 55 DIM.

compared with wk 3 (53.5\% vs. $35.6 \%$, respectively; $P$ $=0.01)$.

\section{Phenotypes Associated with CL Status}

We found a strong association between URTS and CL status at wk 3 and 7 (both $P<0.0001$ ). Cows that had a G3 and G4 score at wk 3, or a G2, G3, or G4 score at wk 7, had a reduced likelihood of having CL present compared with cows that had a G1 score (Table 2). Similarly, we observed a strong association between UHS and CL status at wk 3 and 7 (both $P$ $<0.0001$ ), in which cows with a normal UHS had a greater likelihood of having CL present than those with an abnormal UHS (Table 2).

We found associations at wk 3 and 7 between CL status and BCS $(P=0.05$ at wk $3 ; P<0.0001$ at wk $7)$ and between CL status and parity $(P=0.0007$ at wk $3 ; P=0.005$ at wk 7 ; Table 3 ). Cows with low BCS and primiparous cows had a lower likelihood of

Table 2. Association between ultrasound reproductive tract score, uterine health status, and CL status at wk 3 and 7 postpartum ${ }^{1}$

\begin{tabular}{|c|c|c|c|c|c|c|}
\hline Variable & \multicolumn{3}{|c|}{ Wk 3} & \multicolumn{3}{|c|}{ Wk 7} \\
\hline \multicolumn{7}{|l|}{ URTS } \\
\hline $\mathrm{G} 2$ & $66.6^{\mathrm{a}}(435 / 653)$ & $0.2(0.14-0.31)$ & & $79.7^{\mathrm{b}}(943 / 1,182)$ & $0.5(0.27-1.05)$ & \\
\hline G3 & $40.9^{\mathrm{b}}(644 / 1,574)$ & $0.04(0.02-0.06)$ & & $46.3^{\mathrm{c}}(265 / 572)$ & $0.1(0.03-0.34)$ & \\
\hline G4 & $18.7^{\mathrm{c}}(59 / 314)$ & $0.04(0.01-0.1)$ & & $50^{c}(11 / 22)$ & $0.04(0.02-0.09)$ & \\
\hline Abnormal & $37.2(703 / 1,888)$ & $0.3(0.22-0.46)$ & & $68.6(1,219 / 1,776)$ & $0.1(0.08-0.17)$ & \\
\hline
\end{tabular}

${ }^{\mathrm{a}-\mathrm{c}}$ Different superscripts within a category indicate significant differences $(P<0.05)$.

${ }^{1} \mathrm{G} 1=$ spoke-wheel-shaped lumen; G2 = spoke-wheel-shaped lumen with an enlarged center filled with a small volume $(>2 \mathrm{~mm}, \leq 5 \mathrm{~mm}$ diameter) of fluid of mixed echogenicity; G3 = stellate-shaped lumen filled with a moderate volume ( $>5 \mathrm{~mm}, \leq 10 \mathrm{~mm}$ diameter $)$ of fluid of mixed echogenicity; G4 = circular lumen filled with a large volume ( $>10 \mathrm{~mm}$ diameter $)$ of fluid of mixed echogenicity; OR $=$ odds ratio; UHS $=$ uterine health status; URTS = ultrasound reproductive tract score; wk $3=14$ to 27 DIM; wk $7=42$ to 55 DIM.

${ }^{2}$ Normal UHS group at wk 3 postpartum was composed of cows with a G1 or G2 uterine score and at wk 7 by cows with a G1 uterine score. 
Table 3. Association between BCS, parity, and CL status at wk 3 and 7 postpartum ${ }^{1}$

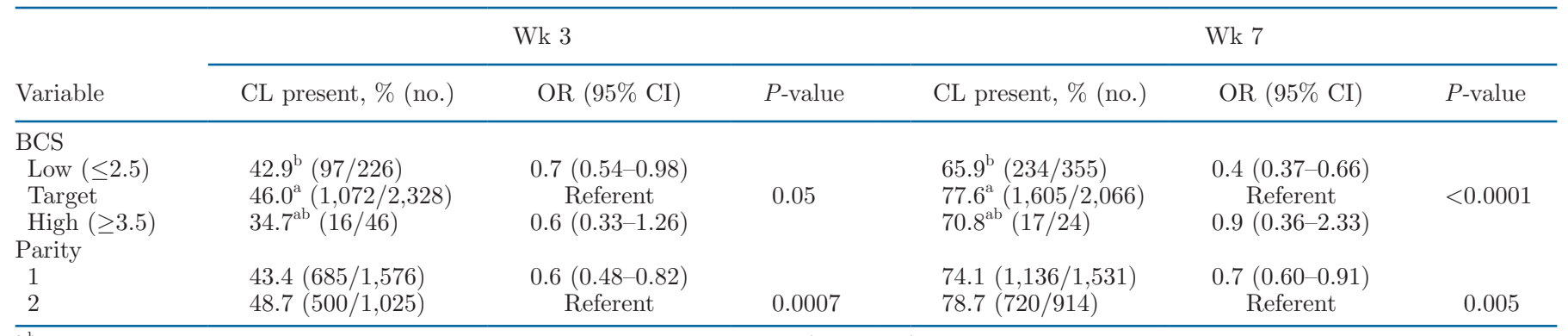

${ }^{\mathrm{a}, \mathrm{b}}$ Different superscripts within a category indicate significant differences $(P<0.05)$.

${ }^{1} \mathrm{OR}=$ odds ratio; wk $3=14$ to 27 DIM; wk $7=42$ to 55 DIM.

having CL present than target BCS and multiparous cows, respectively. We found no associations between BCS change and CL status at wk 3 and $7(P=0.67$ at wk $3 ; P=0.58$ at wk 7 ).

We observed an association between metabolic status and CL status $(P=0.03)$ at wk 3 . Cows that had good and moderate metabolic status were 8.9 (95\% CI 5.57-11.73) and 6.6 (95\% CI 1.51-29.60) times more likely to have CL present, respectively, than cows that had poor metabolic status.

\section{Phenotypes Associated with CL Status Change}

We observed associations between CL status change and both UHS $(P<0.0001$ at wk 3 and 7$)$ and BCS $(P<0.0001$ at wk $3 ; P=0.0008$ at wk 7$)$ at wk 3 and 7 postpartum. Cows with an abnormal UHS were more likely to be CL-absent3_7 and less likely to be CLpresent3_7 than cows that had a normal UHS (Figure 1). Similarly, cows with low BCS were more likely to be CL-absent3_7 and less likely to be CL-present3_7 than cows with target BCS (Figure 2).

\section{Phenotypes Associated with Uterine Health Status}

We found associations between UHS and CL status $(P<0.0001$ at wk 3 and 7$), \operatorname{BCS}(P=0.01$ at wk 3 ; $P=0.02$ at wk 7$)$, and parity $(P=0.05$ at wk $3 ; P=$ 0.009 at wk 7; Table 4 and Table 5). Cows that did not have a CL present had a greater likelihood of having an abnormal UHS than cows that had CL present at wk 3 and 7 . In cows classified as CL absent, the presence (i.e., anestrous cows) or absence (i.e., deep anestrous cows) of a large follicle was not associated with differences in UHS at wk $3(P=0.31)$ or $7(P=0.78$; Table 4).

Low BCS $(\leq 2.5)$ at wk 3 was associated with increased odds of having an abnormal UHS compared with target and high BCS (Table 5). We found no sig- nificant association between either BCS change $(P=$ 0.78 at wk $3 ; P=0.44$ at wk 7$)$ or metabolic status $(P$ $=0.61$ at wk $3 ; P=0.43$ at wk 7 ) and UHS.

Primiparous cows had a greater likelihood of having an abnormal UHS at both wk $3(P=0.05)$ and wk $7(P$ $=0.009)$ compared with multiparous cows (Table 5$)$.

\section{Phenotypes Associated with Metabolic Status and DIM}

Metabolic status was associated with parity at wk 3 $(P=0.0002)$ and wk $7(P=0.003)$. A greater proportion of primiparous cows had good metabolic status at wk 3 (39.1\% vs. $31.0 \%)$ and wk 7 (56.4\% vs. $48.6 \%)$ compared with multiparous cows.

Overall, DIM at which cows were evaluated at the wk 3 visit was associated with CL status and UHS (both $P<0.0001)$. The likelihood of CL being present was greater $(+8$ percentage points) and the likelihood of having an abnormal UHS was less (-14 percentage points) in the late category compared with the mid and early categories (Figure 3).

\section{PTA for Individual Genetic Traits and Fertility Sub-index}

We found an association between PTA for CIV and CL status at wk $3(P=0.05)$. Cows in the quartile with the most negative PTA for CIV had greater likelihood of having CL present at wk 3 postpartum than cows in the other 3 quartiles (Table 6). We found evidence for an association between PTA for milk protein percentage and CL status at wk 3 and wk 7 (both, $P=$ $0.10)$. Cows in the quartile with the greatest PTA for milk protein percentage (i.e., $>0.12$ ) were 0.7 (95\% CI $0.59-0.96)$ and 0.7 (95\% CI 0.51-1.00) times less likely to have CL present at wk 3 and 7 than cows in the quartile with the lowest PTA for milk protein percentage (Supplemental Table S1; https://doi.org/10.3168/ 


\section{NORMAL UHS WK 3}

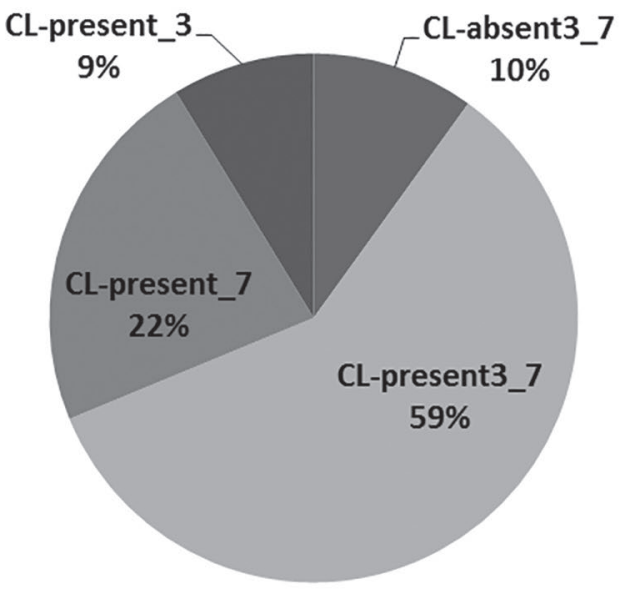

\section{ABNORMAL UHS WK 3}

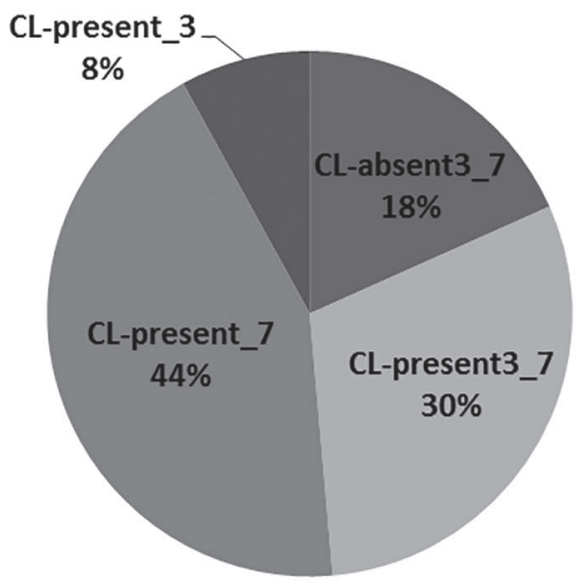

NORMAL UHS WK7

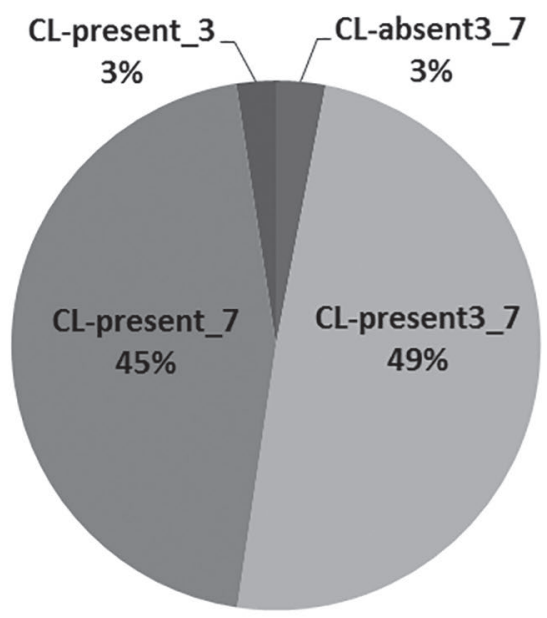

\section{ABNORMAL UHS WK7}

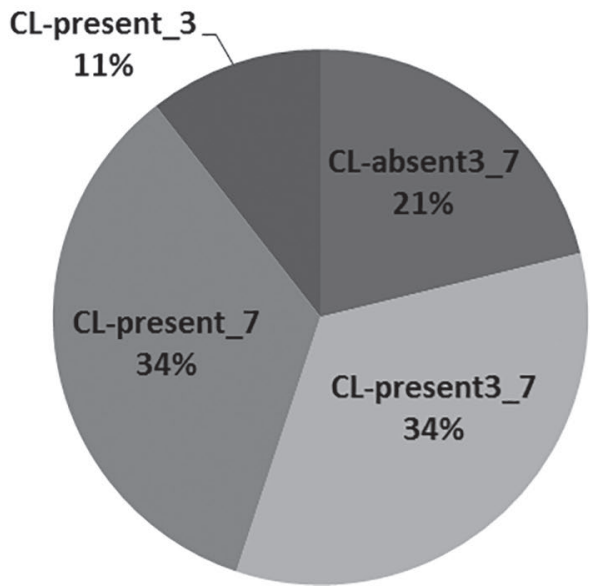

Figure 1. Left: Distribution frequency of corpus luteum (CL) status change in cows with normal and abnormal uterine health status (UHS) at wk 3 postpartum (effect of CL status change, $P<0.0001$ ). Right: Distribution frequency of CL status change in cows with normal and abnormal UHS at wk 7 postpartum (effect of CL status change, $P<0.0001$ ). CL-absent3_7 = corpus luteum not present at wk 3 or 7 ; CL-present3_7 $=$ corpus luteum present at wk 3 and 7 ; CL-present $7=$ corpus luteum present at wk 7 only; CL-present $3=$ corpus luteum present at wk 3 only.

jds.2018-16000). Fertility sub-index was not associated with any postpartum phenotype in this study (Supplemental Tables S1 and S2; https://doi.org/10.3168/jds .2018-16000).

We found an association between PTA for CIV and UHS at wk $3(P=0.01)$. Cows in the 2 quartiles with the greatest PTA for CIV (i.e., $>-1.2$ and $>-2.25$ to $\leq-1.2)$ had greater incidence of abnormal UHS $(+5$ percentage points) than the quartile with the most negative PTA for CIV (Table 7). We found a lower incidence $(P=0.09)$ of abnormal UHS at wk 7 in cows in the quartile with the greatest PTA for survival (i.e., $>2$ ).

\section{DISCUSSION}

It has been reported previously that BCS at parturition, nadir BCS, BCS at AI (Hoedemaker et al., 2009; Roche et al., 2009), number of cycles before first insemination (Darwash et al., 1997), uterine health (Sheldon et al., 2009; Rojas Canadas et al., 2020), metabolic status (Lucy et al., 2014; Rojas Canadas et al., 2020), parity (Tanaka et al., 2008; Rojas Canadas et al., 2020), and genetic merit for fertility traits (Butler, 2014; Butler and Moore, 2018) are all factors that affect reproductive performance in lactating dairy cows. Nevertheless, most of the preceding studies have 
LOW BCS

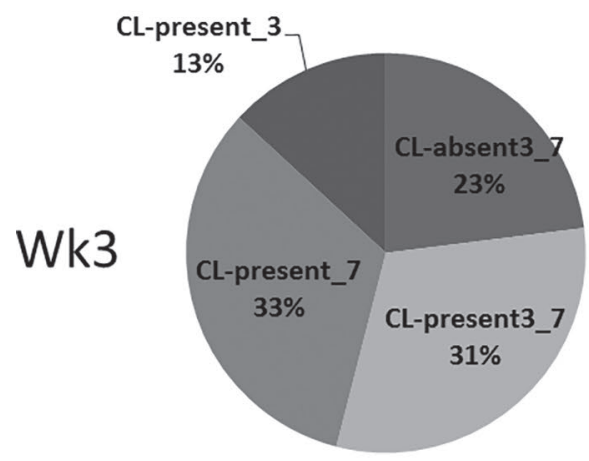

LOW BCS

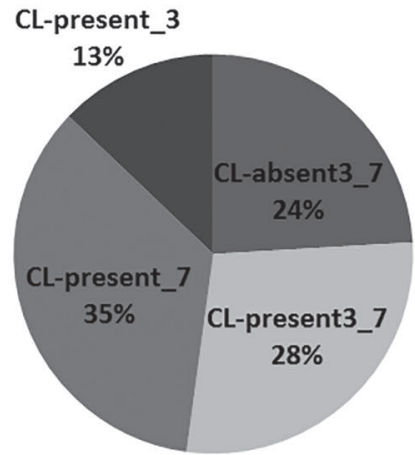

TARGET BCS

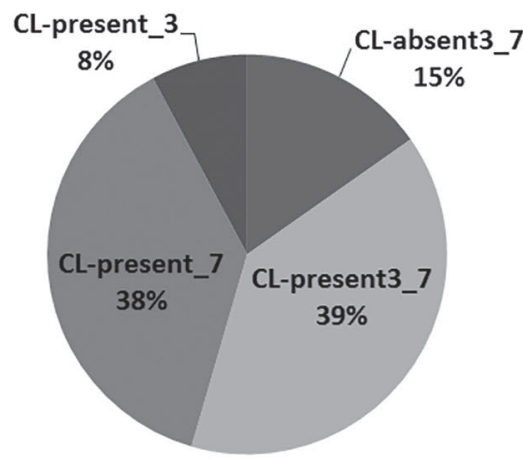

TARGET BCS

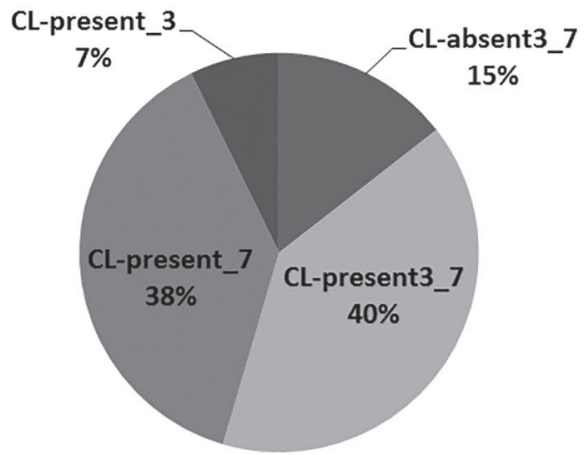

HIGH BCS

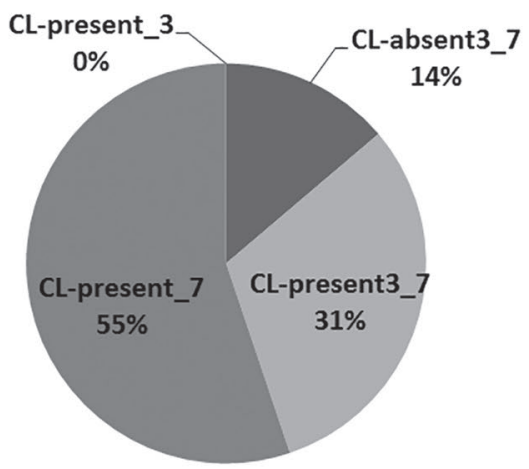

HIGH BCS

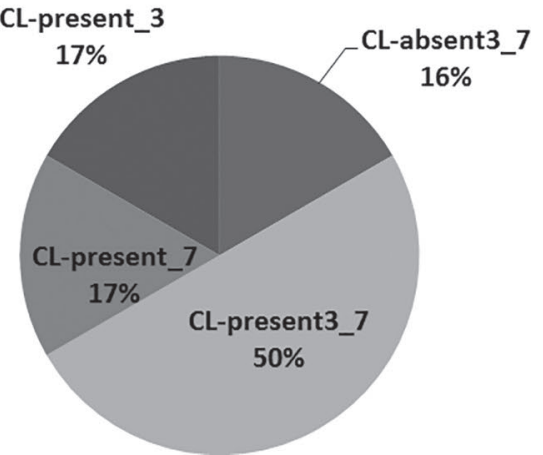

Figure 2. Top: Distribution frequency of CL status change in cows with different BCS categories at wk 3 (effect of CL status change, $P<$ 0.0001). Bottom: Distribution frequency of CL status change in cows with different BCS categories at wk 7 (effect of CL status change, $P<$ 0.0008). CL-absent3_7 = corpus luteum not present at wk 3 or 7; CL-present3_7 = corpus luteum present at wk 3 and 7 ; CL-present7 $=$ corpus luteum present at wk 7 only; CL-present $3=$ corpus luteum present at wk 3 only.

looked at a single phenotype in isolation, and the linkages between these phenotypes have remained poorly understood. In the present study, we conducted a robust and comprehensive study of postpartum fertil- ity phenotypes, and we identified strong associations between many of these phenotypes, and with individual genetic traits. Our research highlights the importance of selecting for improved fertility traits and imposing

Table 4. Association between corpus luteum (CL) status, depth of anestrous, and uterine health status at wk 3 and 7 postpartum ${ }^{1}$

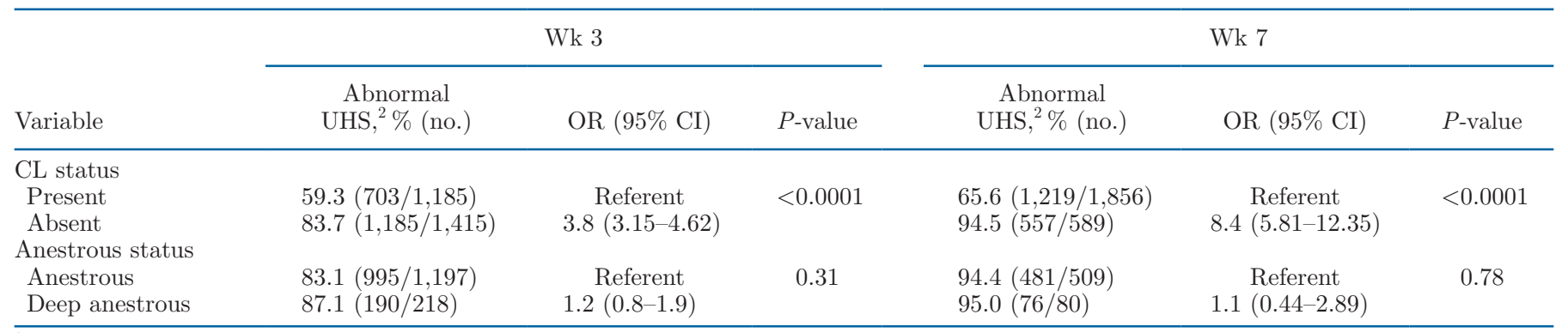

${ }^{1} \mathrm{G} 2=$ spoke-wheel-shaped lumen with an enlarged center filled with a small volume ( $>2 \mathrm{~mm}, \leq 5 \mathrm{~mm}$ diameter $)$ of fluid of mixed echogenicity; $\mathrm{G} 3=$ stellate-shaped lumen filled with a moderate volume $(>5 \mathrm{~mm}, \leq 10 \mathrm{~mm}$ diameter $)$ of fluid of mixed echogenicity; G4 = circular lumen filled with a large volume ( $>10 \mathrm{~mm}$ diameter) of fluid of mixed echogenicity; OR = odds ratio; UHS $=$ uterine health status; wk $3=14$ to 27 DIM; wk $7=42$ to 55 DIM.

${ }^{2}$ Abnormal UHS group at wk 3 postpartum was composed of cows with G3 or G4 uterine score and at wk 7 by cows with a G2, G3, or G4 uterine score. Significant differences at $P<0.05$. 
Table 5. Association between BCS, parity, and uterine health status at wk 3 and 7 postpartum ${ }^{1}$

\begin{tabular}{|c|c|c|c|c|c|c|}
\hline \multirow[b]{2}{*}{ Variable } & \multicolumn{3}{|c|}{ Wk 3} & \multicolumn{3}{|c|}{ Wk 7} \\
\hline & $\begin{array}{c}\text { Abnormal } \\
\text { UHS, }^{2} \% \text { (no.) }\end{array}$ & OR $(95 \%$ CI $)$ & $P$-value & $\begin{array}{c}\text { Abnormal } \\
\text { UHS, }{ }^{2} \% \text { (no.) }\end{array}$ & OR $(95 \% \mathrm{CI})$ & $P$-value \\
\hline \multicolumn{7}{|l|}{ BCS } \\
\hline Target & $71.8^{\mathrm{a}}(1,672 / 2,327)$ & Referent & 0.01 & $71.4^{\mathrm{a}}(1,476 / 2,066)$ & Referent & 0.02 \\
\hline Low & $79.2^{\mathrm{b}}(179 / 226)$ & $1.6(1.16-2.36)$ & & $78.5^{\mathrm{b}}(279 / 355)$ & $1.5(1.11-2.03)$ & \\
\hline High & $78.2^{\mathrm{ab}}(36 / 46)$ & $1.1(0.56-2.53)$ & & $87.5^{\mathrm{ab}}(21 / 24)$ & $1.4(0.45-4.85)$ & \\
\hline \multicolumn{7}{|l|}{ Parity } \\
\hline 2 & $70.3(720 / 1,024)$ & Referent & 0.05 & $69.8(638 / 914)$ & Referent & 0.009 \\
\hline
\end{tabular}

${ }^{\mathrm{a}, \mathrm{b}}$ Different superscripts within category indicate significant differences $(P<0.05)$.

${ }^{1} \mathrm{G} 2=$ spoke-wheel-shaped lumen with an enlarged center filled with a small volume ( $>2 \mathrm{~mm}, \leq 5 \mathrm{~mm}$ diameter) of fluid of mixed echogenicity; G3 = stellate-shaped lumen filled with a moderate volume $(>5 \mathrm{~mm}, \leq 10 \mathrm{~mm}$ diameter $)$ of fluid of mixed echogenicity; G4 = circular lumen filled with a large volume ( $>10 \mathrm{~mm}$ diameter) of fluid of mixed echogenicity; OR = odds ratio; UHS $=$ uterine health status; wk $3=14$ to 27 DIM; wk $7=42$ to 55 DIM.

${ }^{2}$ Abnormal UHS group at wk 3 postpartum was composed of cows with G3 or G4 uterine score and at wk 7 by cows with a G2, G3, or G4 uterine score.

herd management routines to maximize the proportion of cows with favorable postpartum phenotypes.

\section{Ovarian CL Status}

One of the fertility targets in seasonal-calving systems is that $\geq 70 \%$ of the herd is detected in estrus by mating start date (Butler, 2014). Early resumption of ovulatory ovarian activity after parturition is one of the key steps to restore breeding potential in grass-based systems. In the present study, $76.9 \%$ of the cows had CL present by wk 7 postpartum. It is likely that the high proportion of cows that had CL present at wk 7 is at least partly a reflection of the subpopulation of cows used within the study herds (first and second calvers), and the decision to only use cows with no clinical disease and that calved earlier than $30 \mathrm{~d}$ before the mating start date. In previous research, Santos et al. (2009) and Cerri et al. (2004) reported similar proportions of cows that had resumed estrous cyclicity $(75.9 \%$ at 65 DIM and $77.5 \%$ at 65 DIM, respectively), albeit at a later stage of lactation. In our study, cows with the most negative PTA for CIV (i.e., genetically superior) had a greater likelihood of having CL present by wk 3 postpartum, highlighting the benefit of selecting for fertility traits.

The results of this study also highlight the associations between CL status and other postpartum phenotypes. Cows with G3 and G4 uterine scores were less likely to have CL present at wk 3 and 7 postpartum than cows with a G1 uterine score, in agreement with previous studies (Opsomer et al., 2000; Gilbert, 2011). Similarly, CL status change was also associated with UHS in the present study. Cows with an abnormal
UHS at wk 3 and 7 were more likely not to have at least $1 \mathrm{CL}$ at wk 3 and 7 postpartum than cows with a normal UHS. In the companion paper to the present study (Rojas Canadas et al., 2020), we reported that CL status at wk 3 was not strongly associated with subsequent reproductive performance, but that there was a favorable association at wk 7 . Furthermore, we found associations between UHS at wk 3 and 7 and reproductive performance (Rojas Canadas et al., 2020). Because of the strong association between CL status and uterine health observed in the present study, early resumption of cyclicity is a favorable phenotype for subsequent reproductive performance.

We observed strong associations between CL status and uterine health in the present study. Uterine infection alters ovarian function through effects mediated by endotoxins and cytokines, resulting in reduced androstenedione and estradiol production, and fewer LH receptors on granulosa cells (Williams et al., 2008). Endotoxins also alter GnRH pulses and LH secretion from the hypothalamus and pituitary gland, respectively, and reduce pituitary responsiveness to $\mathrm{GnRH}$, preventing the preovulatory LH surge (Herath et al., 2006; Williams et al., 2008). Conversely, Gobikrushanth et al. (2016) reported no differences in CL status on d 35 and 65 postpartum in Canadian dairy cows with different categories of endometritis.

In the present study, low BCS $(\leq 2.5)$ at wk 3 and 7 was associated with a reduced likelihood of having CL present compared with cows that had a BCS $\geq 2.75$. Furthermore, CL status change was also associated with BCS; a greater proportion of cows with target or high BCS had CL present at both wk 3 and 7 exams, and at the wk 7 exam only, compared with cows that 
had low BCS. Although we did not measure BCS at calving in the present study, our results were consistent with previous studies (Santos et al., 2009; Roche et al., 2015) that reported delayed resumption of luteal function in cows with low BCS.

It should be noted that assessment of CL status at wk 3 and 7 was based on single-visit exams (presence/ absence of CL), which likely overestimates the proportion of anestrous cows at both visits (i.e., imminent and recent ovulations not included). It was not logistically possible to conduct follow-up clinical examinations of cows without a CL 1 wk later to confirm anestrous status. Similarly, in a practical commercial setting, it is not economically viable to conduct repeat clinical

\section{Abnormal UHS}

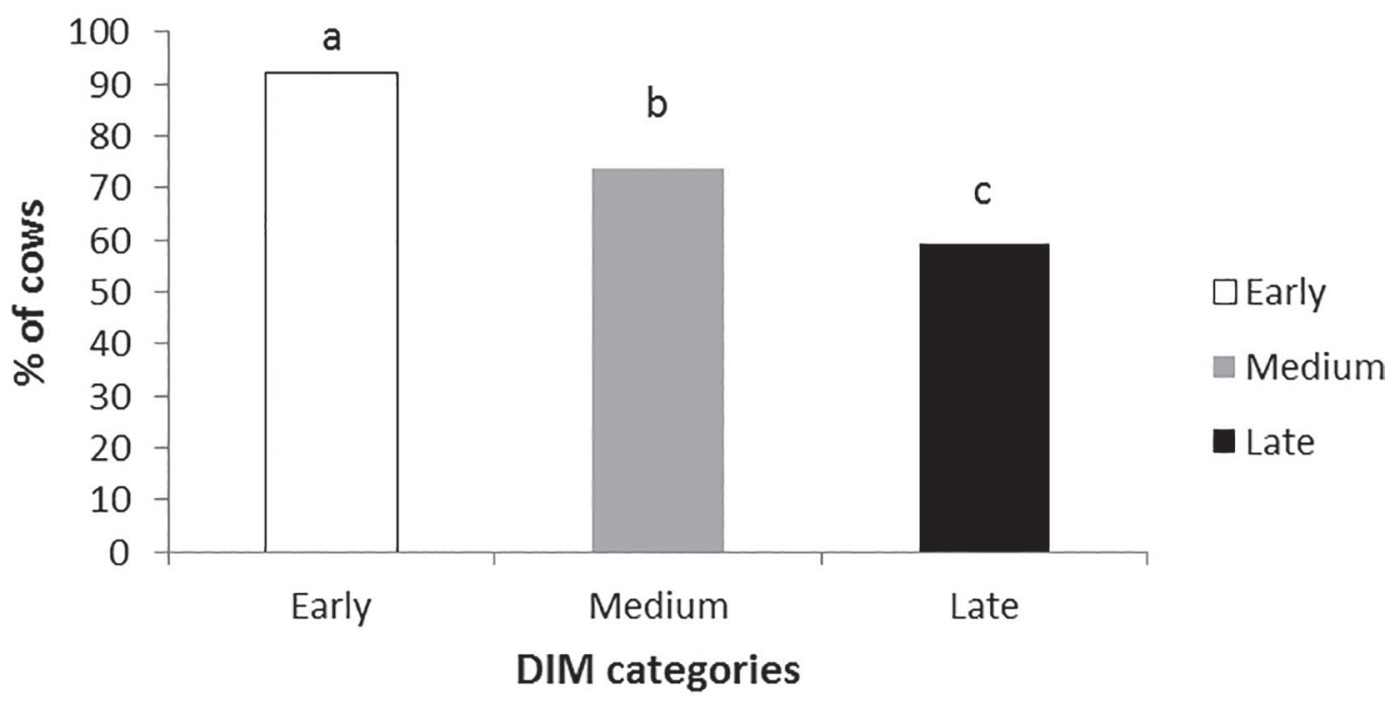

\section{CL present}

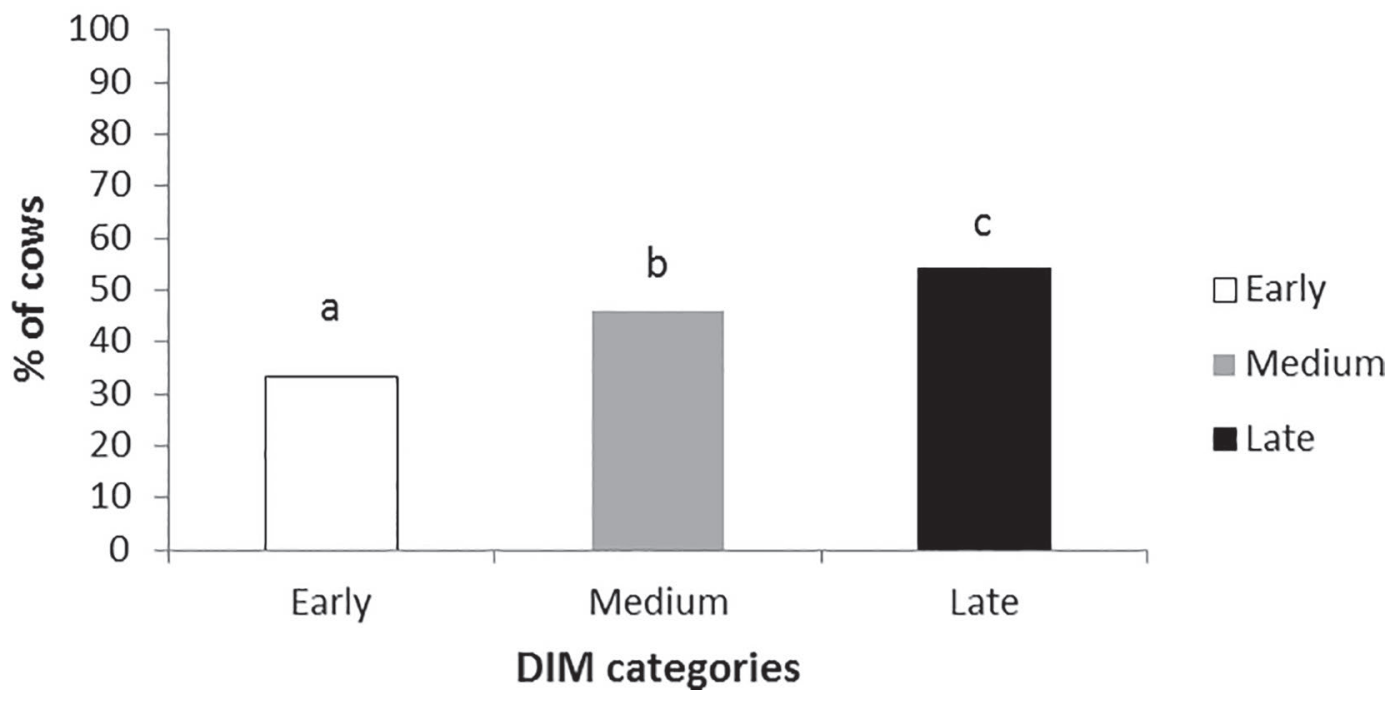

Figure 3. Top: Distribution frequency of abnormal uterine health status (UHS) in different DIM categories at wk 3 postpartum $(P<0.0001)$. Bottom: Distribution frequency of CL present in different DIM categories at wk 3 postpartum $(P<0.0001)$. Bars with different lowercase letters differ $(P<0.0001)$. 
Table 6. Association between individual genetic traits (survival and calving interval) and CL status at wk 3 and 7 postpartum ${ }^{1}$

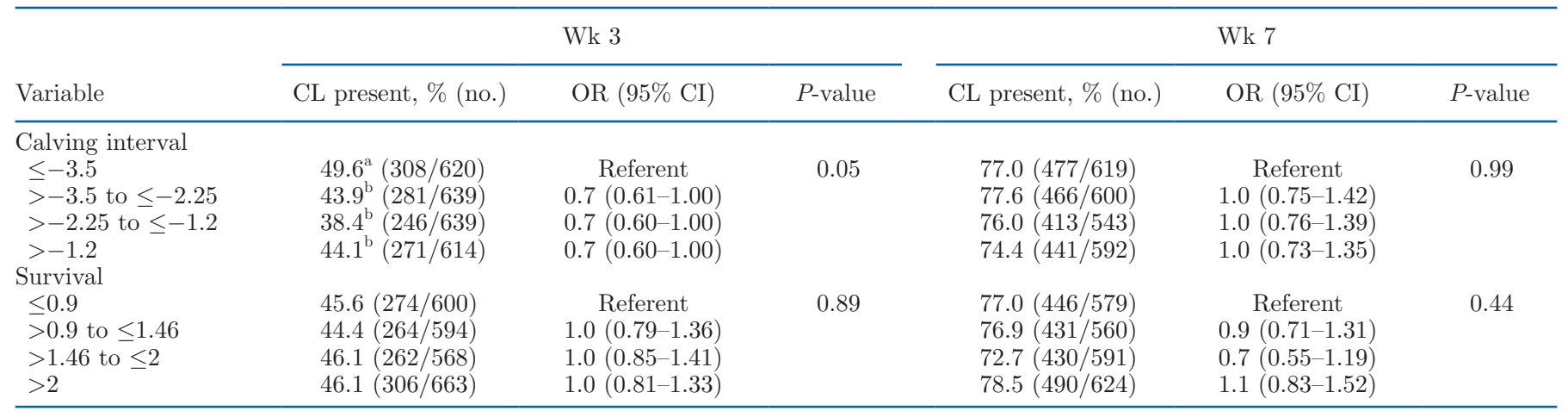

${ }^{\mathrm{a}, \mathrm{b}}$ Different superscripts within category indicate significant differences $(P<0.05)$.

${ }^{1} \mathrm{OR}=$ odds ratio; wk $3=14$ to 27 DIM; wk $7=42$ to 55 DIM.

exam visits on commercial dairy farms; hence, our data set reflects what would likely be available following a clinical examination at wk 3 or 7 postpartum.

\section{Uterine Health}

After calving, the uterus is exposed to microbial pathogens, and the development and severity of uterine infection depends upon the species of bacteria involved, their prevalence, and the immune response of the cow (Sheldon et al., 2002). At the cellular level, defense against bacterial contaminants in the uterus is provided by uterine leukocytes and polymorphonuclear cells. Polymorphonuclear cells are recruited to the infected uterus by chemotactic factors such as IL-8 (Christoffersen et al., 2010). The risk factors responsible for uterine infection may include altered follicle development and function (Sheldon et al., 2002), delayed resumption of cyclicity (Galvão et al., 2010b), altered follicle steroidogenesis (Green et al., 2011), and greater postpartum fatty acid and BHB concentrations (Hammon et al., 2006). The results of the present study clearly indicate a strong association between CL status and UHS, in which cows that were classified as CL absent were more likely to have an abnormal UHS at wk 3 and 7 than cows that had CL present, in agreement with Galvão et al. (2010b). The evacuation of uterine contents that occurs during estrus and the beneficial effect of elevated concentrations of estradiol during proestrus and estrus on neutrophil function in the uterus are likely mechanisms (Gilbert, 2011; Sheldon et al., 2014).

We observed a strong association between UHS and BCS in the present study; cows with a low BCS had a greater likelihood of an abnormal UHS at wk

Table 7. Association between individual genetic traits (survival, calving interval, milk yield, and milk protein percentage), fertility sub-index and uterine health status at wk 3 and 7 postpartum ${ }^{1}$

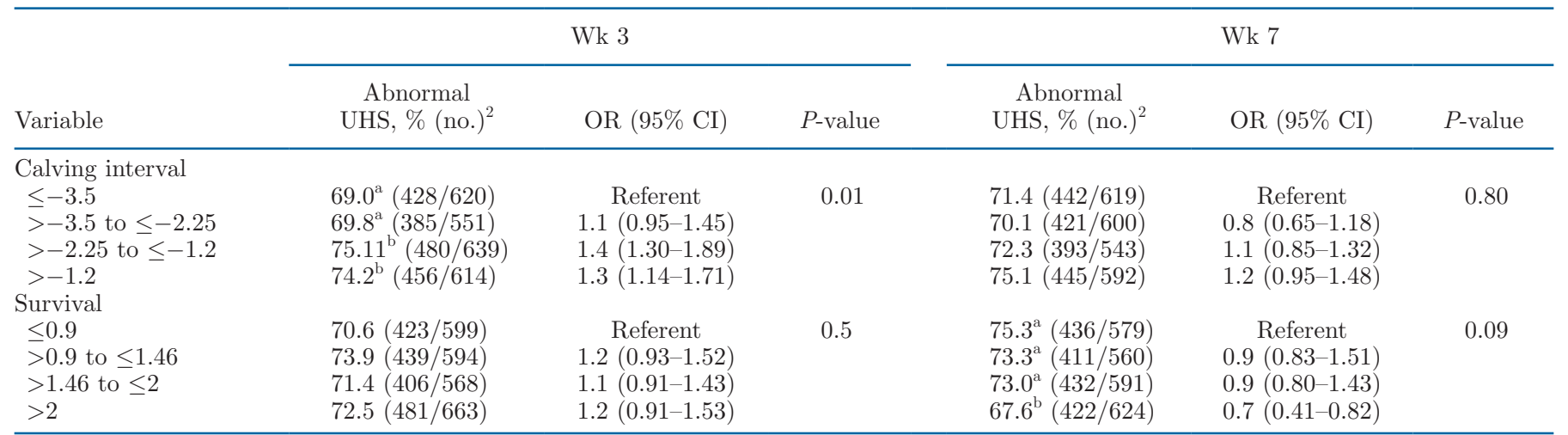

${ }^{\mathrm{a}, \mathrm{b}}$ Different superscripts within category indicate significant differences $(P<0.05)$.

${ }^{1} \mathrm{G} 2=$ spoke-wheel-shaped lumen with an enlarged center filled with a small volume $(>2 \mathrm{~mm}, \leq 5 \mathrm{~mm}$ diameter $)$ of fluid of mixed echogenicity; $\mathrm{G} 3=$ stellate-shaped lumen filled with a moderate volume $(>5 \mathrm{~mm}, \leq 10 \mathrm{~mm}$ diameter $)$ of fluid of mixed echogenicity; G4 = circular lumen filled with a large volume ( $>10 \mathrm{~mm}$ diameter) of fluid of mixed echogenicity; OR = odds ratio; UHS $=$ uterine health status; wk3 $=14$ to 27 DIM; $w \mathrm{wk}=42$ to 55 DIM.

${ }^{2}$ Abnormal UHS group at wk 3 postpartum was composed of cows with G3 or G4 uterine score and at wk 7 by cows with a G2, G3, or G4 uterine score. 
3 and 7 postpartum than cows with a target BCS, in agreement with Hoedemaker et al. (2009) and Kadivar et al. (2014). Although we did not measure BCS at calving in the present study, it is plausible to suggest that cows with a low BCS during early lactation were likely exposed to more severe negative energy balance than cows at target BCS, resulting in greater lipomobilization and increased circulating fatty acid and BHB concentrations. This metabolic environment decreases polymorphonuclear cell activity, increasing the risk of uterine infections (Hammon et al., 2006; Galvão et al., 2010a).

\section{BCS Change}

BCS at calving, postpartum BCS change, and BCS nadir have been identified as risk factors affecting health (Shin et al., 2015), production (Roche et al., 2015), and reproductive performance in dairy cows (Buckley et al., 2003; Roche et al., 2007). In the present study, BCS change between wk 3 and 7 was not associated with any phenotype studied during the postpartum period. This discrepancy could be attributed to the time BCS was measured and the maintenance of target BCS in most cows throughout the study period. In the present study, $63.8 \%$ of the cows did not lose BCS between wk 3 and 7, compared with Santos et al. (2009), in which $32.3 \%$ that did not lose BCS between parturition and first service. It is likely that a BCS measurement at or before parturition is necessary to quantify the effect of BCS loss. It should also be noted that we did not enroll cows with periparturient health problems in the present study, and this might have influenced our findings in relation to BCS change.

\section{Metabolic Status}

The severity of negative energy balance influences the concentration of blood metabolites, including plasma fatty acids (Ospina et al., 2013) and BHB (McArt et al., 2013). Postpartum blood concentrations of fatty acids, BHB, and glucose have been used to predict incidence of ketosis, displaced abomasum, and uterine infections (Shin et al., 2015; Ospina et al., 2010b; reviewed by Esposito et al., 2014). Nevertheless, we found no association between metabolic status and UHS, in agreement with Burke et al. (2010). This disagreement between studies might be explained by differences in milk production system [pasture-based in Burke et al. (2010) and the present study vs. confinement system in Ospina et al. (2010b)], DIM when blood sample for fatty acids and BHB measurement was collected [wk 3 and wk 7 in the present study vs. 14 to $2 \mathrm{~d}$ prepartum and 2 to $14 \mathrm{~d}$ postpartum in Ospina et al. (2010b)], and categorization of metabolic status carried out in the present study (good, moderate, and poor). On the other hand, metabolic status in the present study was associated with CL status at wk 3: cows with good and moderate metabolic status were more likely to have CL present than cows with poor metabolic status. This was consistent with the well-characterized associations between energy balance status, LH pulse frequency, and postpartum interval to first ovulation (Canfield and Butler, 1990).

\section{Parity}

Primiparous cows were 37 and $26 \%$ less likely to have CL present, and 19 and $29 \%$ more likely to have abnormal UHS at wk 3 and 7 postpartum, respectively, compared with multiparous cows. These findings were in agreement with Tanaka et al. (2008) and Goshen and Shpigel (2006). Primiparous cows had greater concentrations of plasma fatty acids than multiparous cows 1 wk before parturition and during the early postpartum period (Wathes et al., 2007). Elevated blood concentrations of fatty acids and ketones before parturition have been associated with reduced periparturient immune function and uterine disease (Hammon et al., 2006), which in turn influences postpartum interval to first ovulation (Sheldon et al., 2002). It is possible that primiparous cows are more sensitive to metabolic and endocrine signals during the periparturient and postpartum period, increasing the risk of postpartum uterine infection and delaying the postpartum resumption of ovulation. Primiparous cows had more favorable metabolic status than second-parity cows in the current study: a greater proportion of primiparous cows were in the good metabolic status group at both wk 3 and 7 than multiparous cows. This reflected the lower milk yield from primiparous cows during the postpartum period compared with multiparous cows (Wathes et al., 2007), and the prerequisite for favorable bioenergetic status to support continued skeletal growth.

\section{DIM at First Examination}

Postpartum examination of dairy cows is undertaken to assess early clinical findings and administer therapies if necessary. In the present study, cows examined at wk 3 were categorized as early (14-18 DIM), medium (19-23 DIM), or late (24-28 DIM). The highest rate of CL present and the lowest rate of abnormal UHS were observed in the late group (Figure 1), highlighting the importance of DIM at the time of early postpartum examination. Complete gross involution of the uterus oc- 
curs over a range of 25-30 d postpartum, during which time uterine dimensions reduce to approximately the pregravid state (Hussain and Daniel, 1991); clearance of postpartum uterine infection is hastened by uterine involution (Sheldon et al., 2006). In the present study, the longer interval available to cows in the late category to ovulate a follicle and progress uterine involution at the wk 3 visit compared with cows in the mid and early categories is an important criterion for interpreting results from early postpartum clinical examinations.

\section{PTA and Fertility Sub-index}

In the present study, the genetic trait PTA for CIV was associated with CL status and UHS at wk 3 postpartum. Cows with the most negative PTA for CIV had a greater likelihood of having CL present and having better UHS at wk 3 postpartum. We also found evidence to indicate an association between PTA for survival and UHS at wk 7. In pasture-based systems, cows that do not establish pregnancy during the breeding period are generally culled at the end of that lactation. Prompt resumption of ovulatory ovarian cyclicity is essential to achieve high submission rates during the first $21 \mathrm{~d}$ of the breeding period, reducing the interval of calving to pregnancy and concentrating the period of calving the following year (Butler, 2014). Moreover, an increased number of estrous cycles before first AI has been associated with greater pregnancy rate (Darwash et al., 1997). These findings are in agreement with previous studies from our group (Cummins et al., 2012; Moore et al., 2014), in which cows with good genetic merit for fertility traits had superior uterine health, earlier resumption of cyclicity, shorter estrous cycles, ovulated larger follicles, and greater luteal phase blood progesterone concentrations than cows with poor genetic merit for fertility traits.

\section{CONCLUSIONS}

The observations arising from this study provide evidence that CL status, uterine health, BCS, parity, and individual genetic traits were strongly associated at both wk 3 and 7 postpartum in seasonal-calving, pasture-based lactating dairy cows. Target BCS, good metabolic status, and selecting cows based on PTA for CIV are all expected to enhance uterine health and increase the likelihood of hastening the resumption of estrous cycles during the postpartum period. Further research is necessary to assess associations between phenotypes observed in this study and breeding season reproductive performance in compact calving, pasturebased dairy cows.

\section{ACKNOWLEDGMENTS}

The authors thank the Irish Department of Agriculture, Food and the Marine for funding this project through RSF award 13S528. This study would not have been possible without the support of the 35 commercial dairy farmers. The assistance of numerous undergraduate placement students is also acknowledged.

\section{REFERENCES}

Andersen, J. B., N. Friggens, T. Larsen, M. Vestergaard, and K. L. Ingvartsen. 2004. Effect of energy density in the diet and milking frequency on plasma metabolites and hormones in early lactation dairy cows. J. Vet. Med. A Physiol. Pathol. Clin. Med. 51:52-57.

Buckley, F., K. Sullivan, J. Mee, R. Evans, and P. Dillon. 2003. Relationships among milk yield, body condition, cow weight, and reproduction in spring-calved Holstein-Friesians. J. Dairy Sci. 86:2308-2319.

Burke, C. R., S. Meier, S. McDougall, C. Compton, M. Mitchell, and J. R. Roche. 2010. Relationships between endometritis and metabolic state during the transition period in pasture-grazed dairy cows. J. Dairy Sci. 93:5363-5373.

Butler, S. T. 2014. Nutritional management to optimize fertility of dairy cows in pasture-based systems. Animal 8(Suppl. 1):15-26.

Butler, S. T., and S. G. Moore. 2018. Genetic control of reproduction in dairy cows under grazing conditions. Anim. Reprod. 15(Suppl. 1):933-939.

Butler, W. R. 2003. Energy balance relationships with follicular development, ovulation and fertility in postpartum dairy cows. Livest. Prod. Sci. 83:211-218.

Canfield, R. W., and W. R. Butler. 1990. Energy balance and pulsatile LH secretion in early postpartum dairy cattle. Domest. Anim. Endocrinol. 7:323-330.

Cerri, R. L., J. E. Santos, S. O. Juchem, K. N. Galvão, and R. C. Chebel. 2004. Timed artificial insemination with estradiol cypionate or insemination at estrus in high-producing dairy cows. J. Dairy Sci. 87:3704-3715.

Christoffersen, M., C. D. Baagoe, S. Jacobsen, A. M. Bojesen, M. R. Petersen, and H. Lehn-Jensen. 2010. Evaluation of the systemic acute phase response and endometrial gene expression of serum amyloid A and pro- and anti-inflammatory cytokines in mares with experimentally induced endometritis. Vet. Immunol. Immunopathol. 138:95-105.

Coffey, M. 1992. Genetic trends. Has progress been made in the last six years? Holstein Friesian J. 74:62-63.

Cummins, S. B., P. Lonergan, A. Evans, and S. T. Butler. 2012. Genetic merit for fertility traits in Holstein cows: II. Ovarian follicular and corpus luteum dynamics, reproductive hormones, and estrus behavior. J. Dairy Sci. 95:3698-3710.

Darwash, A., G. Lamming, and J. Wooliams. 1997. The phenotypic association between the interval to post-partum ovulation and traditional measures of fertility in dairy cattle. Anim. Sci. 65:9-16.

Drackley, J. K., T. R. Overton, and G. N. Douglas. 2001. Adaptations of glucose and long-chain fatty acid metabolism in liver of dairy cows during the periparturient period. J. Dairy Sci. 84:E100-E112.

Edmonson, A., I. Lean, L. Weaver, T. Farver, and G. Webster. 1989. A body condition scoring chart for Holstein dairy cows. J. Dairy Sci. 72:68-78.

Esposito, G., P. C. Irons, E. C. Webb, and A. Chapwanya. 2014. Interactions between negative energy balance, metabolic diseases, uterine health and immune response in transition dairy cows. Anim. Reprod. Sci. 144:60-71.

Galvão, K. N., M. J. Flaminio, S. B. Brittin, R. Sper, M. Fraga, L. Caixeta, A. Ricci, C. L. Guard, W. R. Butler, and R. O. Gilbert. 2010a. Association between uterine disease and indicators of neutrophil and systemic energy status in lactating Holstein cows. J. Dairy Sci. 93:2926-2937. 
Galvão, K. N., M. Frajblat, W. R. Butler, S. B. Brittin, C. L. Guard, and R. O. Gilbert. 2010b. Effect of early postpartum ovulation on fertility in dairy cows. Reprod. Domest. Anim. 45:e207-e211.

Garverick, H. A., M. N. Harris, R. Vogel-Bluel, J. D. Sampson, J. Bader, W. R. Lamberson, J. Spain, M. C. Lucy, and R. S. Youngquist. 2013. Concentrations of nonesterified fatty acids and glucose in blood of periparturient dairy cows are indicative of pregnancy success at first insemination. J. Dairy Sci. 96:181-188.

Gilbert, R. O. 2011. The effects of endometritis on the establishment of pregnancy in cattle. Reprod. Fertil. Dev. 24:252-257.

Gobikrushanth, M., R. Salehi, D. Ambrose, and M. Colazo. 2016. Categorization of endometritis and its association with ovarian follicular growth and ovulation, reproductive performance, dry matter intake, and milk yield in dairy cattle. Theriogenology 86:18421849.

Goshen, T., and N. Y. Shpigel. 2006. Evaluation of intrauterine antibiotic treatment of clinical metritis and retained fetal membranes in dairy cows. Theriogenology 66:2210-2218.

Green, M. P, A. M. Ledgard, S. E. Beaumont, M. C. Berg, K. P. McNatty, A. J. Peterson, and P. J. Back. 2011. Long-term alteration of follicular steroid concentrations in relation to subclinical endometritis in postpartum dairy cows. J. Anim. Sci. 89:3551-3560.

Hammon, D. S., I. M. Evjen, T. R. Dhiman, J. P. Goff, and J. L. Walters. 2006. Neutrophil function and energy status in Holstein cows with uterine health disorders. Vet. Immunol. Immunopathol. 113:21-29

Hanrahan, L., N. McHugh, T. Hennessy, B. Moran, R. Kearney, M. Wallace, and L. Shalloo. 2018. Factors associated with profitability in pasture-based systems of milk production. J. Dairy Sci.

Herath, S., H. Dobson, C. Bryant, and I. Sheldon. 2006. Use of the cow as a large animal model of uterine infection and immunity. J. Reprod. Immunol. 69:13-22.

Hoedemaker, M., D. Prange, and Y. Gundelach. 2009. Body condition change ante-and postpartum, health and reproductive performance in German Holstein cows. Reprod. Domest. Anim. 44:167-173.

Hussain, A. M., and R. C. W. Daniel. 1991. Bovine endometritis: Current and future alternative therapy. Zentralbl. Veterinarmed. A 38:641-651.

Kadivar, A., M. R. Ahmadi, and M. Vatankhah. 2014. Associations of prepartum body condition score with occurrence of clinical endometritis and resumption of postpartum ovarian activity in dairy cattle. Trop. Anim. Health Prod. 46:121-126.

Lacetera, N., D. Scalia, U. Bernabucci, B. Ronchi, D. Pirazzi, and A. Nardone. 2005. Lymphocyte functions in overconditioned cows around parturition. J. Dairy Sci. 88:2010-2016.

LeBlanc, S. J., K. Lissemore, D. Kelton, T. Duffield, and K. Leslie. 2006. Major advances in disease prevention in dairy cattle. J. Dairy Sci. 89:1267-1279.

Lucy, M. C., S. Butler, and H. Garverick. 2014. Endocrine and metabolic mechanisms linking postpartum glucose with early embryonic and foetal development in dairy cows. Animal 8(Suppl. 1):82-90.

McArt, J. A., D. V. Nydam, G. R. Oetzel, T. R. Overton, and P. A. Ospina. 2013. Elevated non-esterified fatty acids and $\beta$-hydroxybutyrate and their association with transition dairy cow performance. Vet. J. 198:560-570.

Mee, J. F., F. Buckley, D. Ryan, and P. Dillon. 2009. Pre-breeding ovaro-uterine ultrasonography and its relationship with first service pregnancy rate in seasonal-calving dairy herds. Reprod. Domest. Anim. 44:331-337.

Moore, S. G., T. Fair, P. Lonergan, and S. T. Butler. 2014. Genetic merit for fertility traits in Holstein cows: IV. Transition period, uterine health, and resumption of cyclicity. J. Dairy Sci. 97:27402752 .

Opsomer, G., Y. Gröhn, J. Hertl, M. Coryn, H. Deluyker, and A. de Kruif. 2000. Risk factors for post partum ovarian dysfunction in high producing dairy cows in Belgium: A field study. Theriogenology 53:841-857.

Ospina, P. A., D. V. Nydam, T. Stokol, and T. R. Overton. 2010a. Associations of elevated nonesterified fatty acids and $\beta$-hydroxybutyrate concentrations with early lactation reproductive performance and milk production in transition dairy cattle in the northeastern United States. J. Dairy Sci. 93:1596-1603.

Ospina, P. A., D. V. Nydam, T. Stokol, and T. R. Overton. 2010b. Evaluation of nonesterified fatty acids and $\beta$-hydroxybutyrate in transition dairy cattle in the northeastern United States: Critical thresholds for prediction of clinical diseases. J. Dairy Sci. 93:546554.

Ospina, P. A., J. A. McArt, T. R. Overton, T. Stokol, and D. V. Nydam. 2013. Using nonesterified fatty acids and $\beta$-hydroxybutyrate concentrations during the transition period for herd-level monitoring of increased risk of disease and decreased reproductive and milking performance. Vet. Clin. North Am. Food Anim. Pract. 29:387-412.

Rhodes, F. M., S. McDougall, C. R. Burke, G. A. Verkerk, and K. L. Macmillan. 2003. Invited review: Treatment of cows with an extended postpartum anestrous interval. J. Dairy Sci. 86:1876-1894.

Roche, J. R., K. A. Macdonald, C. R. Burke, J. M. Lee, and D. P. Berry. 2007. Associations among body condition score, body weight, and reproductive performance in seasonal-calving dairy cattle. J. Dairy Sci. 90:376-391.

Roche, J. R., K. A. Macdonald, K. E. Schütz, L. R. Matthews, G. A. Verkerk, S. Meier, J. J. Loor, A. R. Rogers, J. McGowan, S. R. Morgan, S. Taukiri, and J. R. Webster. 2013. Calving body condition score affects indicators of health in grazing dairy cows. J. Dairy Sci. 96:5811-5825.

Roche, J. R., S. Meier, A. Heiser, M. D. Mitchell, C. G. Walker, M. A. Crookenden, M. V. Riboni, J. J. Loor, and J. K. Kay. 2015. Effects of precalving body condition score and prepartum feeding level on production, reproduction, and health parameters in pasture-based transition dairy cows. J. Dairy Sci. 98:7164-7182.

Roche, J. R., N. C. Friggens, J. K. Kay, M. W. Fisher, K. J. Stafford, and D. P. Berry. 2009. Invited review: Body condition score and its association with dairy cow productivity, health, and welfare. J. Dairy Sci. 92:5769-5801.

Rojas Canadas, E., M. M. Herlihy, J. Keneally, J. Grant, F. Kearney, P. Lonergan, and S. T. Butler. 2020. Associations between postpartum phenotypes, cow factors, genetic traits, and reproductive performance in seasonal calving pasture-based lactating dairy cows. J. Dairy Sci. 103:1016-1030. https://doi.org/10.3168/jds 2018-16001.

Santos, J. E., H. M. Rutigliano, and M. F. Sá Filho. 2009. Risk factors for resumption of postpartum estrous cycles and embryonic survival in lactating dairy cows. Anim. Reprod. Sci. 110:207-221.

Sheldon, I. M., D. E. Noakes, A. N. Rycroft, D. U. Pfeiffer, and H. Dobson. 2002. Influence of uterine bacterial contamination after parturition on ovarian dominant follicle selection and follicle growth and function in cattle. Reproduction 123:837-845.

Sheldon, I. M., S. B. Price, J. Cronin, R. O. Gilbert, and J. E. Gadsby. 2009. Mechanisms of infertility associated with clinical and subclinical endometritis in high producing dairy cattle. Reprod. Domest. Anim. 44(Suppl. 3):1-9.

Sheldon, I. M., J. G. Cronin, G. D. Healey, C. Gabler, W. Heuwieser, D. Streyl, J. J. Bromfield, A. Miyamoto, C. Fergani, and H. Dobson. 2014. Innate immunity and inflammation of the bovine female reproductive tract in health and disease. Reproduction 148:R41R51.

Sheldon, I. M., G. S. Lewis, S. LeBlanc, and R. O. Gilbert. 2006 Defining postpartum uterine disease in cattle. Theriogenology 65:1516-1530

Shin, E.-K., J.-K. Jeong, I.-S. Choi, H.-G. Kang, T.-Y. Hur, Y.-H. Jung, and I.-H. Kim. 2015. Relationships among ketosis, serum metabolites, body condition, and reproductive outcomes in dairy cows. Theriogenology 84:252-260.

Tanaka, T., M. Arai, S. Ohtani, S. Uemura, T. Kuroiwa, S. Kim, and H. Kamomae. 2008. Influence of parity on follicular dynamics and resumption of ovarian cycle in postpartum dairy cows. Anim. Reprod. Sci. 108:134-143.

Veerkamp, R. F., P. Dillon, E. Kelly, A. R. Cromie, and A. F. Groen. 2002. Dairy cattle breeding objectives combining yield, survival and calving interval for pasture-based systems in Ireland under different milk quota scenarios. Livest. Prod. Sci. 76:137-151. 
Wathes, D. C., Z. Cheng, N. Bourne, V. J. Taylor, M. P. Coffey, and S. Brotherstone. 2007. Differences between primiparous and multiparous dairy cows in the inter-relationships between metabolic traits, milk yield and body condition score in the periparturient period. Domest. Anim. Endocrinol. 33:203-225.

Williams, E. J., K. Sibley, A. N. Miller, E. A. Lane, J. Fishwick, D. M. Nash, S. Herath, G. C. England, H. Dobson, and I. M. Sheldon. 2008. The effect of Escherichia coli lipopolysaccharide and tumour necrosis factor alpha on ovarian function. Am. J. Reprod. Immunol. 60:462-473.

\section{ORCIDS}

E. Rojas Canadas $\odot$ https://orcid.org/0000-0002-4801-233X

M. M. Herlihy ๑ https://orcid.org/0000-0002-3886-0300

J. Kenneally @ () https://orcid.org/0000-0001-9033-1927

P. Lonergan (1) https://orcid.org/0000-0001-5598-5044

S. T. Butler (1) https://orcid.org/0000-0003-1542-8344 